\title{
Endoscopic sinus surgery in individuals with facial pain due to chronic maxillary sinusitis - a functional controlled study
}

\section{Cirurgia endoscópica de seio da face em indivíduos com dor facial devida a sinusite maxilar crônica - um estudo funcional controlado}

Giuseppe Sanges ${ }^{1}$, Mario Gamerra², Gerardo Sorrentino², Roberto De Luca³, Maddalena Merone ${ }^{4}$, Michele Feleppa ${ }^{5}$, Marcelo Eduardo Bigal ${ }^{6}$

\begin{abstract}
Objective: To measure the intra-sinus pressure and the maxillary sinus functional efficiency (MSFE) in individuals with chronic facial pain after conservative or conventional endoscopic maxillary surgery, as well as in controls. Method: Sinus manometry was performed 5 times during inhalation. Results: The resemblance of pressure values comparing those treated with minimally invasive surgery and controls was remarkable, while traditional surgery significantly decreased intrasinusal pressures. The MSFE was 100\% in the three tested times for controls, close to that in those submitted to minimally invasive surgery (98.3\%, 98.8\%, and 98.0\%) and significantly impaired after conventional surgery $(48.8 \%, 52.1 \%, 48.5 \%, p<0.01)$. All patients submitted to minimally invasive surgery remained pain-free after three months of surgery, relative to $46.7 \%$ of the submitted to conventional surgery $(p<0.05)$. Conclusion: Minimally invasive sinus surgery is associated with functionality of the chambers that resemble what is found in normal individuals.
\end{abstract}

Keywords: facial pain, nasal cavities, manometry, biophysical model, endoscopic surgery.

\section{RESUMO}

Objetivo: Medir a pressão intrasinusal e a eficiência funcional do seio maxilar (EFSM) em indivíduos com dor facial crônica após cirurgia endoscópica maxilar conservadora ou convencional em comparação a pessoas normais. Método: A manometria do seio foi feita 5 vezes durante a inalação. Resultados: A semelhança entre os valores das pressões comparando aqueles tratados com cirurgia minimamente invasiva e os controles foi notável, enquanto que na cirurgia tradicional houve diminuição significativa das pressões intrasinusais. A EFSM foi $100 \%$ nas três vezes testadas nos controles, de modo muito semelhante ao que foi observado naqueles submetidos a cirurgia minimamente invasiva $(98,3 \%, 98,8 \%$, e $98,0 \%)$ e significativamente diminuída naqueles submetidos a cirurgia convencional $(48,8 \%$, $52,1 \%, 48,5 \%, p<0,01)$. Todos os pacientes submetidos a cirurgia minimamente invasiva mantiveram-se sem dor três meses depois da cirurgia, comparados a $46,7 \%$ naqueles submetidos a cirurgia convencional $(p<0,05)$. Conclusão: Cirurgia minimamente invasiva está associada a funcionalidade das câmaras sinusais que se assemelha ao que é observado em indivíduos normais.

Palavras-chave: dor facial, cavidades nasais, manometria, modelo biofísico, cirurgia endoscópica.

The facial sinuses develop as outgrowths from the nasal cavity, hence communicating directly or indirectly to the nose. The ostium meatal complex (OMC) connects the nasal cavity to the paranasal sinuses. Its peculiar structure and shape allows the maxillary sinus to ventilate in a "low pressure system". Accordingly, the occlusion of the OMC results in a slow but progressive increase in the intra-maxillary sinus pressure which, in turn, predisposes to tissue hypoxia, a powerful inducer of nitric oxide (NO) synthesis and pain. It has been demonstrated that NO levels correlate with OMC obstruction ${ }^{1,2,3,4}$.

Sinus headache is a term widely assigned to individuals with facial pain. The inappropriate diagnosis of sinus

${ }^{1}$ Headache and Cervico-Facial Pain Service, A.S.L. NA 3, Naples, Italy;

Surgery Department, "S. Leonardo Hospital”, A.S.L. NA 3, Castellammare di Stabia, Naples, Italy;

${ }^{3}$ Department of Physics “E. R. Caianiello", University of Salerno, Italy;

4"Lyceum Cosenza”, Castellammare di Stabia, Naples, Italy;

${ }^{5}$ Department of Neurology, Hospital “G. Rummo”, Benevento, Italy;

${ }^{6}$ Labrys Biologics Inc, San Mateo CA, USA.

Correspondence: Marcelo E. Bigal; Labrys Biologics Inc San Mateo CA, 4269 Arbor Lane Doylestown Pennsylvania 188902, USA;

E-mail: mbigal@labrysbiologics.com

Conflict of interest: There is no conflict of interest to declare. 
headache can lead to unnecessary diagnostic studies, surgical interventions, and medical treatments ${ }^{5,6}$. Although the vast majority of individuals diagnosed as having sinus headaches represent diagnostic errors, headache and facial pain of rhinogenic origin are real and often seen in clinical practice $^{7}$. In some circumstances, the etiology of pain resides on the maxillary sinuses and is secondary to chronic infection ${ }^{5,6}$. Surgeries are sometimes indicated to treat these cases ${ }^{6}$.

Biophysical models suggest that excessive enlargement of the sinus ducts worsens, rather than improves the ventilation of the cavity ${ }^{3}$. Therefore, it is recommended that the standard anatomy is respected as much as possible during surgery, in order to achieve optimal functional result s. $^{\text {. }}$ Evidence to substantiate the best surgical approaches in patients with facial pain secondary to maxillary problems is still lacking. Accordingly, herein we measured the air flow, intra-sinus pressure, and the maxillary sinus functional efficiency (MSFE) in individuals with chronic facial pain and surgical indication to maxillary sinus surgery before and after conservative or conventional endoscopic surgery, in order to correlated the MSFE with pain outcomes.

\section{METHOD}

Sample consisted of 30 patients that were consecutively seen in a specialty clinic with clinical symptoms suggestive of unilateral maxillary sinusitis and diagnostic confirmation by computerized tomography of the face and by nasal endoscopy. All participants had moderate to severe facial pain, sub-continuous with exacerbations (often due to barometric changes), made worse by bending forward or by lying down.

To be eligible for this study, participants had to experience pain and symptoms of sinusitis for at least three months, as well as to have failed to conventional medical therapy, as recommended by the 2012 guidelines of the Infectious Diseases Society of America ${ }^{6}$. To be documented as failure, subjects had to have properly used several antibiotics regimens including amoxicillin/clavulanate, azithromycin, clarithromycin, trimethoprim/sulfamethoxazole or ciprofloxacin.

After consenting to participate, volunteers were randomized into one of two groups as follows:

- Group A: Submitted to minimally invasive functional endoscopic sinus surgery (FESS) of the $\mathrm{OMC}^{9}$. This approach preserves the anatomical of the OMC, through minimal enlargement of the maxillary ostium.

- Group B: Submitted to conventional FESS, which includes ethmoidectomy and massive enlargement of the maxillary ostium ${ }^{10}$.

Both procedures are routinely performed as standard of care for such situations ${ }^{11,12,13,14}$, and did not represent surgical innovations.

\section{Procedures}

Since manometry consists of the evaluation of the gauge pressure between two cavities in which air is present, it can only be performed when effective air exchange into these structures is present (it cannot be performed when the sinus is obstructed). Accordingly, manometry was conducted 30 days after the surgical procedure once ventilation of the maxillary cavity had been restored. The measurements were compared with those obtained from controls $(n=20)$, who had attended the same clinic but had nose or sinus disorders excluded. They were not subjected to the nose endoscopy for this study, but as part of their medical care, in order to thoroughly exclude any pathology or anatomical anomaly (e.g., concha bullosa, paradoxical turbinate, pneumatized agger nasi, septal spur). They consented to participate in this study as controls.

Manometry was performed using a customized digital nose and sinus manometer (Gamerra-MGl ${ }^{\mathrm{TM}}$ ) (Figure 1), connected to a rubber tube and a steel probe. The probe was positioned in the maxillary sinus ostium. The instrument was first introduced in the middle meatus with the probe pointing upwards, and subsequently rotated to form an angle of $120^{\circ}$ (clockwise in the left nasal cavity and counterclockwise in the right nasal cavity) through the infundibulum of the maxillary sinus ostium. Accordingly, the probe was positioned just behind the uncinate process, and its proper position was confirmed by endoscopy (Figure 2).

The subjects were asked to breath through the nose. Pressure values were collected before starting inhalation and every second after the onset of inhalation, for four seconds. At time 0 (start test time) and at time 4 (end of testing) pressures were obviously equal to 0.00 mbar (serving as checks to the validity of the system). Tests were conducted after a previous acclimation of the patient at a given

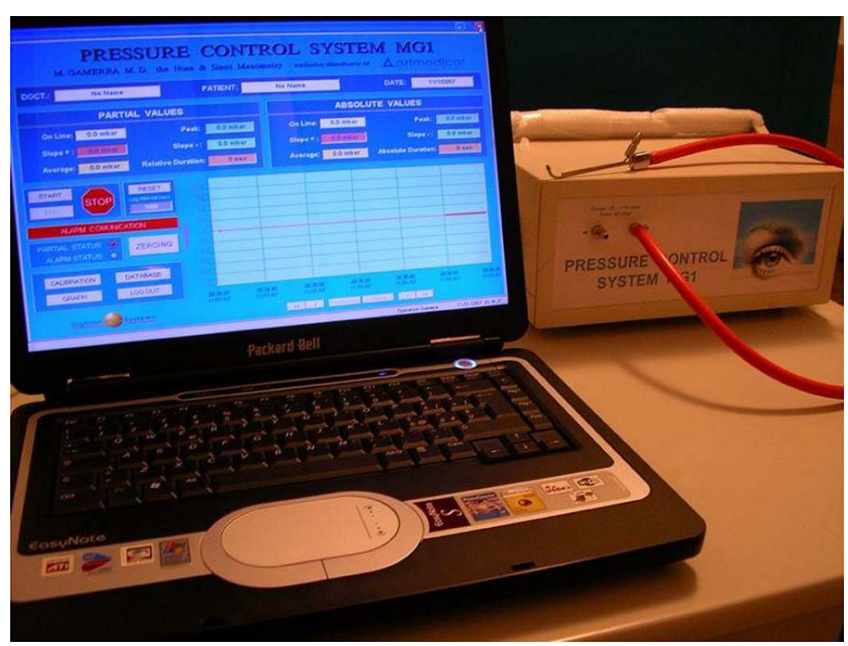

Figure 1. Digital manometer connected to a rubber tube and a steel probe (top; right), as well as the data recording system. 


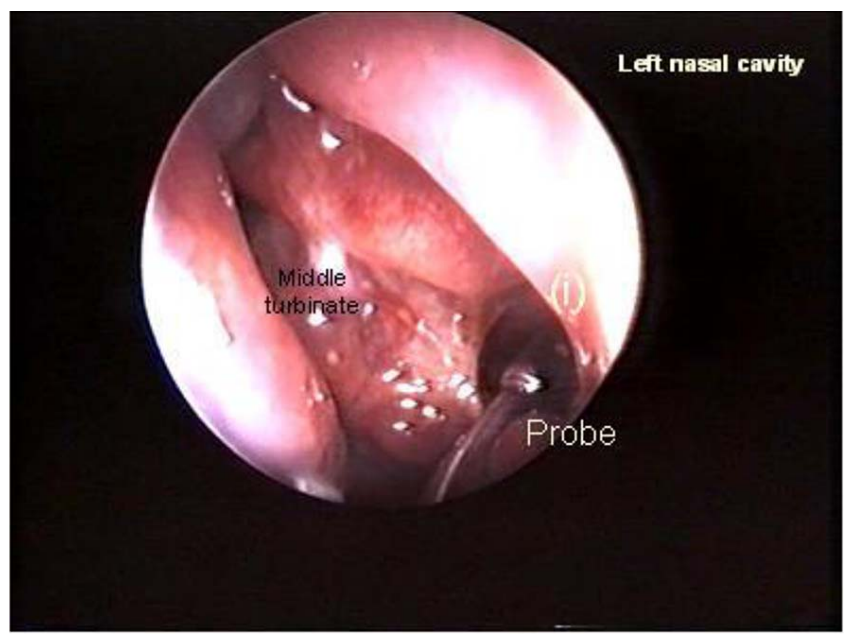

Figure 2. Endoscopic view while positioning of the probe in the maxillary sinus ostium.

temperature and humidity, to reach the environmental requirements for the optimal function of the instrument ${ }^{10,11}$.

Based on the observed parameters, the MSFE was calculated as the ratio between pressure values $(\Delta p)$ observed in Group A or Group B p and the corresponding pressure values $\left(\Delta p_{\text {Standard }}\right)$ of the control group $\left(M S F E \equiv \frac{\Delta p}{\Delta p_{\text {Standard }}} \times 100\right)$

Headache characteristics were collected using a daily headache diary, for the duration of the study.

Descriptive statistics and testing for normality were conducted for the variables presented herein. Values were contrasted using the paired (within group) and unpaired (across groups) Student T test.

The study and consent forms were approved by the Ethics Committee of "San Leonardo Hospital", Azienda Sanitaria Locale Napoli 3, Naples.

\section{RESULTS}

Demographic characteristics of cases $(n=30,50 \%$ men, mean age $=42.6$ years) and controls $(n=20,50 \%$ men, mean age $=40.2$ years) were very similar.

Figure 3 displays the mean manometry values as a function of treatment group. The resemblance of pressure values comparing Group A (minimally invasive surgery) and controls is remarkable. It is also evident that individuals in Group B had substantially decreased intracavity pressures during the entire inhalation period. For example, 1 second after the onset of inhalation, mean values were -1.38 for controls, -1.30 in Group A, and -0.09 in Group B ( $p<0.001$ contrasting Group B vs. Group A and controls - no significant differences comparing Group A and controls). At time 2,

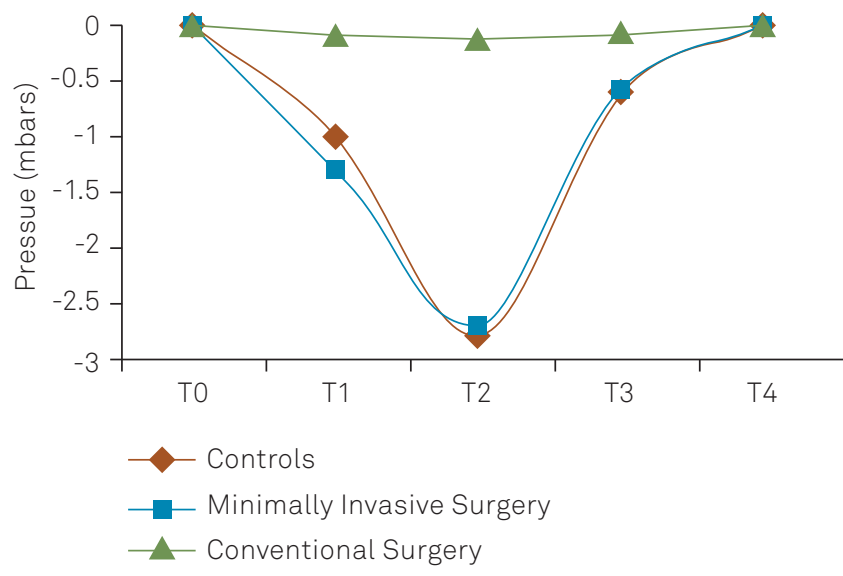

Figure 3. Mean pressure values at five consecutive times, obtained in controls (blue curve), Group A (orange curve) and Group B (brown curve).

mean values were respectively $-2.75,-2.70$ and -0.11 ( $\mathrm{p}<0.001$ contrasting Group B vs. Group A and controls no significant differences comparing Group A and controls). At time 3, values were -0.61 both for controls and Group A, and -0.09 for Group B $(\mathrm{p}<0.001$ contrasting Group B vs. Group A and controls - no significant differences comparing Group A and controls).

The MSFE was $100 \%$ in the three tested times for controls. In group A they were similar and to what had been observed for controls (98.3\%, 98.8\%, and 98.0\%), while in group B, values were significantly different $(48.8 \%, 52.1 \%$, $48.5 \%, \mathrm{p}<0.01$ for all comparison times).

All patients submitted to minimally invasive surgery remained pain-free after three months of surgery, relative to 7 patients $(46.7 \%)$ submitted to conventional surgery $(p<0.05)$.

\section{DISCUSSION}

Headaches of rhinogenic origin illustrate an interesting paradox. Little is known about their pathophysiology, mechanisms and prevalence; yet, the concept that these headaches are of importance is widely accepted (vide the frequency to which headaches are simply diagnosed as being "sinus headaches") ${ }^{15,16}$. A necessary step to change this background is to identify a recognizable source of rhinogenic pain (e.g. trough neuroimaging) and then to proceed to anatomical descriptions as a prelude to understanding the pathophysiology of this form of pain. In a prior study, we estimated the endo-sinusal pressure in patients with fronto-turbinalis sinus expansion suffering from daily headaches in which contact points had been excluded ${ }^{15}$. We found that restoration of the sinus pressure was associated with clinical improvement.

Similar problem may happens when the maxillary sinuses have their ventilation impaired ${ }^{15,17,18}$. Sometimes, 
surgical indication exists in order to address the anatomical cause of the problem and consequent pain. In the past, approaches were aggressive, requiring inferior meatal antrostomy and the radical sublabial antrostomy as described by Caldwell and Luc ${ }^{17,18}$. These approaches have been largely replaced by FESS, which allows better diagnostic assessment of the nasal cavities and close monitoring of postoperative progress ${ }^{19,20}$. Nonetheless, FESS can also be conducted at different degrees of invasiveness.

Accordingly, herein we we contrasted outcomes of endoscopic nasal sinus surgery performed with two different degrees of invasiveness. To the best of our knowledge, this had not yet been conducted. In our Group B, the uncinate process was completely resected. Instead, in Group A we performed a "partial inferior uncinectomy"3,19,20. We found that minimally invasive surgery is associated with better clinical outcomes in terms of resolution of pain and optimal functional levels (ventilation), that are identical to those without intervention (controls) and very different than in those submitted to more radical surgeries (Group B). Although the study was not designed to measure pain improvement, it did happen more often in those with minimally invasive surgery relative to conventional approaches.
The structure and shape of the OMC allows the maxillary and frontal sinuses to ventilate in "low pressure systems". This biophysical model ${ }^{3}$ favors approaches that aim not only to correct the pathology but also to correct the anatomical anomalies with the consequence of the restoration of optimal ventilation. Both methods tested here are adequate to address the underlying pathology but, as demonstrated by our data, they yield very different physiological outcomes. Minimally invasive surgery yielded virtually normal MSFE values while the conventional approach compromised nearly $50 \%$ of the MSFE that was half compromised, and this was not optimal. Accordingly, we demonstrated that minimally invasive surgery minimizes variations to the sinus ventilation by preserving the biologic mechanisms that regulate the physiology of ventilation of the sinus cavities. This is associated with functionality of the chambers that resemble normal individuals. We also provided preliminary evidence that facial pain outcomes were different as a function of the procedure. Future studies should expand on our findings, and more meticulously assess headache features. Future studies should also collect long-term follow-up data, focusing on whether recidivism of sinusitis varies as a function of surgical approach, or if facial pain remission persists in the long-term.

\section{References}

1. Andersson JA, Cervin A, Lindberg S, Uddman R, Cardell LO. A decrease in maxillary sinus pressure, as seen in upper airway allergy or infection, results in an increase in upper airway nitric oxide levels. Acta Otolaryngol. 2002;122:520-523.

2. Campos A, Solomons NB, Armengot M, Zapater E, Basterra J. Role of nasosinusal endoscopic surgery in the treatment of headache and facial pain of rhinogenic origin. J.Acta Otorrinolaringol Esp 1998;49:615-620.

3. Gamerra M, De Luca R. Un modello semplice per descrivere gli effetti sulla ventilazione sinusale del flusso d'aria immessa nella cavità nasale. Giornale di fisica 2004;45:225-228.

4. Gamerra M, Bruno R, Bruno E, Pagano G. The nose function and aesthetic. Ann. Otorhinolaringol Iber-Amer 2004;31:307-323.

5. Cady RK, Dodick DW, Levine HL, et al. Sinus headache: a neurology, otolaryngology, allergy, and primary care consensus on diagnosis and treatment. Mayo Clin Proc 2005;80:908-916.

6. Chow AW, Benninger MS, Brook I, et al. "IDSA clinical practice guideline for acute bacterial rhinosinusitis in children and adults". Clin Infect Dis 2012;5:72-112.

7. EJ Eross, DW Dodick, MD Eross. The sinus, allergy and migraine study (SAMS) Headache, 2014;44:462.

8. Stammberger $\mathrm{H}$. Endoscopic endonasal surgery concepts in the treatment of recurring rhynosinusitis. Part II. Surgical technique. Otolaryngol Head Neck Surg 1986;94:147-156.

9. Kass ES, Fabian RL, Montgomery WW. Manometric study of paranasal sinus mucoceles. Ann Otol Rhinol Laryngol 1999;108:63-66.

10. Kass ES, Salman S, Montgomery WW. Manometric study of complete occlusion in chronic maxillary atelectasis. Laryngoscope. 1996;106:1255-1258.
11. Behrbohm H, Kaschke O. Die minimal invasive endoskopiche Chirurgie der Nase und der Nasennebenhohlen. Stuttgart: G Fischer Verl., 1994.

12. Cook PR, Begegni A, Bryant WC, Davis WE. Effect of partial middle turbinectomy on nasal airflow and resistance. Otolaryngol Head Neck Surg. 1995;113:413-419.

13. Caldwell GW. Diseases of the accessory sinuses of the nose, and an improved method of treatment of suppuration of the maxillary antrum. J New York Medic, 1893;58:526-528.

14. Luc H. Une nouvelle methode operatoire pour la cure radicale et rapide de l'empyeme chronique du sinus maxillaire. Archiv internat laryngologie, d'otologie rhinologie, 1897:10;77-93.

15. Sanges G, Feleppa M, Gamerra M, et al. Fronto-turbinalis sinus expansion and headache. Curr Pain Headache Rep. 2011;15:308-313.

16. Lin SH, Ho CY. Paranasal sinus pathologies in patients presenting with headache as the primary symptom. Cephalalgia. 2006;26:423-427.

17. Senocak D, Senocak M. Sinonasal pathology and headaches. Rhinology. 2004;42:8-14.

18. Bertrand BM, Robillard TA. Comparative study of standard radiology, sinuscopy and sinusomanometry in the maxillary sinus of the adult (about 465 maxillary sinuses). Rhinology 1985;23:237-246.

19. Forsgren K, Fukami M, Penttilä M, et al. Endoscopic and CaldwellLuc approaches in chronic maxillary sinusitis: a comparative histopathologic study on preoperative and postoperative mucosal morphology. Ann Otol Rhinol Laryngol 1995;104:350-357.

20. Penttilä MA, Rautiainen ME, Pukander JS, et al. Endoscopic versus Caldwell-Luc approach in chronic maxillary sinusitis: comparison of symptoms at one-year follow-up. Rhinology 1994;32:161-165. 